\title{
LA CRÍTICA DE LA TEOLOGÍA POLÍTICA EN TOLAND*
}

\author{
POR \\ FCO. JAVIER ESPINOSA ${ }^{1}$ \\ Universidad de Castilla-La Mancha
}

\section{RESUMEN}

Toland (1670-1722) fue un pensador que tenía como objetivos luchar por la libertad, la tolerancia religiosa y la sucesión protestante al trono de Gran Bretaña. Quería demostrar que no hay nada en el cristianismo contrario a la razón y que, por tanto, todas las ideas eran accesibles a todos, incluso a los pobres y a los ignorantes. Así intentaba acabar con el poder de las jerarquías religiosas. Frente a los intentos conservadores de utilización política de la religión, defendía «la unidad sin uniformidad».

PALABRAS CLAVE: Toland; tolerancia; Ilustración; cristianismo; protestantismo; crítica de la religión; Era Moderna.

\section{THE CRITICISM OF POLITICAL THEOLOGY IN TOLAND}

\begin{abstract}
Toland (1670-1722) was a thinker who set himself the goal of fighting for freedom, religious tolerance and the Protestant succession to the throne of Great Britain. He wanted to show that there is nothing contrary to reason in Christianity and, therefore, every idea is accessible to all people, not excepting the poor and the illiterate. That way he was trying to destroy the power of religious hierarchies. Against the conservative attempts to use religion politically, he campaigned for "unity without uniformity». KEY WORDS: Toland; Tolerance; Enlightenment; Christianity; Protestantism, Religious criticism; Modern Age.
\end{abstract}

Cómo CITAR ESTE ARTículo / CITATION: Espinosa, F. J. 2018. «La crítica de la teología política en Toland». Hispania Sacra 70, 141: 95-104. https://doi.org/10.3989/hs.2018.009

\author{
Recibido/Received 09-05-2017 \\ Aceptado/Accepted 09-06-2017
}

\section{UN HOMBRE LIBRE}

Toland fue un pensador que ha estado un tanto enterrado durante dos siglos, entre 1760 y 1960, aproximadamente. Y ahora que ha sido desenterrado y empieza a haber trabajos sobre él y ediciones de sus obras (aunque no todo está bien editado, ni menos aún traducido a los principales idiomas), no hay un consenso acerca de su figura y sus ideas. Por ejemplo, para M. Jacob² no era un filósofo, sino un mero propagandista; para G. Brykman, editora del monográfico de la Revue de Synthèse dedicado a Toland,

\footnotetext{
* Este trabajo se adscribe al proyecto Prismas filosófico-morales de las crisis: hacia una nueva pedagogía sociopolítica (FFI2013-42395-P), financiado por el MICINN de España.

1 Javier.Espinosa@uclm.es / ORCID iD: http://orcid.org/00000002-1833-2228

2 Cfr. Jacob 1969: 330.
}

quizá sea un filósofo pequeño, pero es un espíritu fuerte que abre la puerta de la llustración ${ }^{3}$; para Morillas, autor de una tesis doctoral sobre su pensamiento, es uno de los principales pensadores, pues su filosofía «se nos presenta como fundamental para la comprensión de la Europa de los siglos XVIII y XIX». ${ }^{4} \mathrm{Y}$ si en vez de preguntarnos por su valor para la historia del pensamiento, nos hacemos la pregunta de quién era realmente, las respuestas son muy diversas: para Brow era «un conspirador que vivió en un mundo de conspiraciones $»^{5}$; para Champion, una especie de intelectual francés de los sesenta con ambiciones deconstructivas y artimañas discursivas ${ }^{6}$; y para lofrida, un luchador a favor

3 Cfr. Brykman 1995: 229.

4 Morillas 2008: cap. «Conclusión». Citaré esta tesis doctoral según el capítulo y sin número de página, porque no está paginada.

5 Brown 2012: 1-19.

6 Cfr. Champion 2003: 14. 
del pueblo sencillo. ${ }^{7}$ ¿Fue un ateo, un deísta, un reformador que buscaba el retorno al cristianismo primitivo, un latitudinario ${ }^{8}$, un panteísta? ¿Quizá un pensador burlón enmascarado? ¿Un postmoderno avant la lettre que era capaz de ser todas esas personas a la vez, como dice Fouke? ${ }^{9}$ ¿Toland fue y es un enigma? ${ }^{10}$

John Toland nació en 1670 en el extremo más norte de Irlanda en un ambiente católico. A los 16 años se pasó a la fe protestante:

Siendo educado desde la cuna en la más burda superstición e idolatría, Dios tuvo a bien hacer de mi propia razón, y de la razón de los que hacían uso de la suya, los afortunados instrumentos de mi conversión. Así me acostumbré muy pronto al ejercicio del análisis y de la investigación, y me enseñé a mí mismo a no hacer cautivo mi entendimiento, ni mis sentidos, de ningún hombre, ni de ninguna comunidad. ${ }^{11}$

Estudió en Edimburgo donde obtuvo en 1690 el grado de Magister Artium. Luego entró en contacto con disidentes presbiterianos bajo la guía del pastor Daniel Williams, que le otorgará una beca para estudiar en Holanda, en las universidades de Leiden y de Utrecht, y así volver después a defender este cristianismo presbiteriano disidente del anglicanismo. Esta estancia fue crucial porque allí conoció a personajes muy importantes en la crítica de la religión, como van Limborch y Le Clerc, o el pensamiento de Spinoza.

Volverá hecho un freethinker (así se calificará él a sí mismo en uno de sus Memoriales ${ }^{12}$, escrito al final de su vida) y cercano al movimiento de los latitudinarios. Toland entró en contacto con los whigs y sus principales líderes, sobre todo, con Robert Harley, y, sirviéndole, se dedicó a ser propagandista de los whigs más radicales y republicanos, editando las principales obras de Sidney, Milton y Harrington.

En este momento de su vida, entre 1692-1694 era un apasionado de las discusiones en los coffeehouses, de modo que se decía que hasta se le enviaba la correspondencia allí, como si fuera el sitio donde vivía. ${ }^{13}$ En 1695 fue a Londres para la edición de su Christianity Not Mysterious, que primero saldrá anónimamente y al año siguiente con su nombre en la portada. Las discusiones en los coffeehouses y la publicación de esta obra le pusieron en el foco como uno

\footnotetext{
7 Cfr. lofrida 1983: 57-66.

8 A los old wihgs se les llamaba a veces «latitudinarios», es decir, los que tienen una manga más ancha y menos dogmática en las cuestiones doctrinales, predicando la tolerancia religiosa y defendiendo la importancia de la razón en las cuestiones teológicas (frente a la High Church anglicana conservadora y a los calvinistas puritanos). En su primera obra, y quizá la más importante, Christianity Not Mysterious, Toland cita en la portada una frase de uno de los más señalados latitudinarios, J. Tillotson: «no tenemos mejor evidencia de que un hombre está equivocado que oírle atacar a la razón, lo que significa que la razón está contra él».

9 Cfr. Fouke 2007: 188. Champion también dice que tenía una identidad personal escurridiza (cfr. Champion 2003: 4)

10 Cfr. Champion 2003: 2.

11 Toland 1696: VIII-IX. Aunque hay una primera edición de 1696, reeditada recientemente (Mcguinness, Harrison y Kearney 1997), he preferido ésta segunda de 1696, porque Toland añadió bastantes párrafos para esta edición. A partir de ahora citaré esta edición con las siglas "CNM: Christianity not Mysterious». Todas las traducciones de todas las citas son mías.

12 Toland 1726a: vol. II, 230.

13 Cfr. Morillas 2008: cap. «La concepción de la filosofía y el filósofo en Toland».
}

de los principales sujetos a atacar por parte de las jerarquías religiosas de la High Church. Su libro fue tan conocido que tuvo 54 refutaciones en pocos años. Las violentas críticas a su obra hicieron que se retirase a Irlanda, pero allí arreciaron y no sólo se quemó públicamente su obra, sino que se pidió castigar al autor. Para defenderse publicó tres escritos, A Defence (1697), An Apology (1702), y Vindicius Liberius (1702).

Toland no era un teórico de la política ni un filósofo político. Era un panfletista al servicio de una causa política, que muchas veces fue paralela a la acción política de los whigs. Podríamos decir que su leitmotiv fue la libertad. Por eso decía en el prefacio a su edición de la obra de Sidney que la libertad es lo más importante y de lo que depende el bienestar del pueblo. Y una inscripción en un grabado en las páginas primeras de su edición de la obra de Harrington pone Tolandus libertati sacravit, lo que podríamos pensar que es el resumen de su vida: Toland consagró su vida a la defensa de la libertad. ${ }^{14}$

Si tenemos que elegir un segundo elemento configurador de su vida, señalaríamos la tolerancia religiosa. En Mangoneutes, que es la cuarta parte de la última obra que publicó en vida, Tetradymus (de 1720), decía que «la libertad civil y la tolerancia religiosa habían sido los dos principales objetivos de todos sus escritos». ${ }^{15}$

$Y$, si dando un paso más, tuviéramos que señalar un tercer elemento de su existencia, entonces apuntaríamos a la defensa de la sucesión protestante al trono de Inglaterra. Por eso en el Memorial antes citado indica que los tres principios inalterables en su vida han sido «la libertad civil, la tolerancia religiosa y la sucesión protestante al trono». ${ }^{16}$

Estas tres ideas son el reverso del enemigo que criticará con ardor durante toda su vida: el catolicismo. Por eso no defendió nunca tolerancia alguna para con los católicos, pues éstos defendían el poder absoluto de los monarcas y el imperio del papado en la vida política. Eran todo lo contrario de la libertad civil, la tolerancia religiosa y la sucesión protestante al trono. También estaba enfrentado a los tories y la High Church, a los que veía cercanos al catolicismo, en cuanto que defendían una monarquía absoluta, un cierto acercamiento a Francia y ciertas simpatías por Jacobo II y su hijo, que pretendían restaurar el catolicismo en Inglaterra.

Toland colaborará con los principales líderes whig, Harley y el filósofo Shaftesbury, guardando el difícil equilibrio de mantener el radicalismo republicano de los antiguos whigs y apoyar la monarquía de Guillermo de Orange, el nuevo compromiso de los whigs. ${ }^{17}$ Su obra más importante en política es Anglia libera, de 1701 . Piensa que los republicanos, que inicialmente estaban en contra de todo tipo de monarquía, y cuyo lema era la defensa de la libertad, deben apoyar un gobierno de monarcas protestantes, pero tolerantes y limitados en sus derechos por el parlamento. Para un republicano como Toland tampoco era muy difícil defender una monarquía como la de Guillermo III, pues éste había sido elegido por el parlamento a causa de su virtud, y pensaba

\footnotetext{
${ }^{14}$ Cfr. Ibídem: cap. «La política de Toland: republicanismo y protestantismo».

15 Toland 2004a: 223. Mangoneutes.

16 Toland 1726a: 227.

17 Cfr. Morillas 2008: cap. "La política de Toland: republicanismo y protestantismo».
} 
que para un rey no hay título mejor que la aprobación del pueblo, pues «la voz del pueblo es la voz de Dios». ${ }^{18}$

Esta obra, en la que apoya fuertemente al rey Guillermo III y que el mismo Toland presentó al rey ${ }^{19}$, le dio un gran prestigio y quizá por eso participó en la comitiva que llevó a Sofía de Hannover el acta del parlamento de 1701 en la que se designaba a la casa de Hannover como sucesora al trono de Inglaterra, ya que Guillermo no tenía hijos y había un problema sucesorio. En Alemania conoció también a la hija de Sofía de Hannover, Sofía Charlotte, reina de Prusia, con quien tuvo muchos debates teológicos y filosóficos que le llevaron a escribir Cartas a Serena (1704). Y conoció a Leibniz con el que tuvo algunas discusiones, también a nivel epistolar. En los años siguientes volvió varias veces a Berlín y Hannover.

Un poco antes, había trabado contacto con el pensamiento de Giordano Bruno que será un referente en su metafísica posterior, del que difundirá sus obras y que quizá le fue inclinando hacia el panteísmo. Tenía fama de "ratón de bibliotecas" y le gustaba estudiar libros heterodoxos, evangelios apócrifos, escritos sobre la antigüedad celta... Siempre iba equipado con algún libro de bolsillo y un cuaderno para anotar las ideas que se le iban ocurriendo. ${ }^{20}$

A partir de 1714 empieza a publicar una serie de escritos defendiendo los derechos de los judíos e incluso una cierta interpretación judía del cristianismo. En 1718 publica Nazarenus, en el que, basándose en su descubrimiento del supuesto evangelio de Bernabé y de otro evangelio irlandés, hace una teoría judaizante del cristianismo primitivo y considera que la república mosaica es un modelo para Inglaterra. Quizá la intervención más propiamente original de Toland en la política fue la defensa de los judíos y su lucha para que se les concediera la ciudadanía en un tiempo en el que esto no estaba muy bien visto. Esto lo hizo en su obra Reasons for Naturalizing the Jews de 1714.

Al final de su vida, habiendo perdido ya la confianza de Harley y las funciones propagandísticas del ala radical de los whigs, vivió una temporada de penurias, mucho más profundas todavía cuando se equivocó en la inversión en una compañía marítima que resultó ser un fraude. En 1721 cayó enfermo de asma y murió el 21 de marzo de 1722. Diez días después el periódico The Freeholders Journal de Londres hacía el siguiente resumen:

Sus desgracias deben ser imputadas a su vanidad. Le gustaba sentirse singular en todo (un camino muy fácil para llegar a ser una persona distinguida). Él rechazaba una opinión meramente por el hecho de que un escritor eminente la abrazaba. Tenía nociones de muchos lenguajes, pero no era experto en ninguno. Su estilo era bajo, confuso y desagradable. Puso pretenciosos títulos a sus obras, imitando a algunos antiguos filósofos, en las que le gustaba mucho hablar de sí mismo y eso de la manera más complaciente. Meterse en controversias era para él un deleite, en lo que fue rudo, categórico y siempre estaba en el lado equivocado [...] Ningún hombre que escribiera tanto contra la religión ha hecho tan poco daño. No se sabe si le han tenido más lástima la parte religiosa de la humanidad o desprecio sus compañeros infieles. ${ }^{21}$

18 Toland 1701: 26; cfr. Champion 2003: 122.

19 Cfr. Ibídem: 118.

20 Cfr. Ibídem: 240.

21 Des Maizeaux 1726b: vol. I, XC y XCI.
Esto contrasta con el resumen de su vida que el propio Toland había hecho para el epitafio que preparó para su tumba:

Aquí yace John Toland / que nació cerca de Deriam en Irlanda, / estudió en Irlanda y Escocia, / se hizo mayor en Oxford. / Estuvo más de una vez en Alemania, / pasó su edad madura en Londres. / Cultivador de todo tipo de escritos, / conocedor de más de diez lenguas. / Campeón de la verdad, / defensor de la libertad, / pero no seguidor ni dependiente de nadie. / Ni las amenazas ni los males pudieron doblegarlo, / recorrió hasta el final el camino que había elegido; / prefirió la honestidad al propio interés. / Su espíritu se ha unido al padre etéreo /del cual procedía en su origen. / Su cuerpo, abandonándose a la Naturaleza, / reposa en el seno materno. / Él resurgirá eternamente / pero nunca será el mismo Toland. / Nacido el 30 de noviembre de 1674 / Para lo demás, búscalo en sus escritos. ${ }^{22}$

\section{CÓMO LEER A UN PENSADOR EN PELIGRO}

Se ha cuestionado cómo leer a Toland. La razón principal es que en aquellos tiempos era peligroso exponer directa y abiertamente el pensamiento propio cuando se difería del pensamiento «oficial». El mismo Toland decía en el prefacio de su Christianity not Mysterious que:

[...] tal es la deplorable condición de nuestro tiempo, que un hombre no se atreve a expresar abierta y directamente lo que piensa de las cuestiones religiosas, aunque fueran verdaderas y beneficiosas, si difiere ligeramente de la tradición de su confesión o de lo que es establecido por la ley. Por eso se ve forzado a guardar perpetuo silencio o a expresar sus ideas al mundo de manera paradójica bajo términos prestados o ficticios. ${ }^{23}$

Los peligros a los que se veían expuestos los que disentían de la High Church eran odio, difamación, multas, inhabilitaciones, exilio, prisión y, por último, la muerte: se trataba, en palabras suyas, de una «infernal economía de la fe». ${ }^{24}$ Por eso, Shaftesbury, que durante gran parte de su vida fue una persona cercana a Toland, quizá iba más allá en esta línea y decía:

Si a los hombres se les prohíbe hablar con franqueza y seriedad sobre ciertos temas, entonces lo harán con ironía. Si se les prohíbe hablar totalmente sobre tales temas, o si ellos lo ven realmente peligroso, entonces perfeccionarán su disfraz y lo harán misteriosamente, de modo que casi no puedan ser entendidos, 0 al menos no con claridad, por aquellos que están dispuestos a hacerles daño. ${ }^{25}$

Para recalcar esa dificultad que había de hablar libremente, podemos traer a colación la anécdota que cuenta el mismo Toland:

22 Des Maizeaux 1726a: vol. I, LXXXVIII y LXXXIX.

23 CNM: pref., IV. Pero más adelante dice que la situación no es tan mala, pues «ahora un hombre puede creer de acuerdo con su propio criterio y no según el criterio de la Iglesia, pues hay establecida una tolerancia» e incluso, sigue, "se puede publicar un libro como este sin que se le excomulgue y se confisque el libro» (CNM: 110).

24 Toland 2004a: 67. Clidophorus. A partir de ahora citaremos esta obra con la sigla «C».

25 Shaftesbury, Anthony Ashley Cooper, Conde de 2001: 46. Cfr. Fouke 2007: 11. 
Esto me recuerda lo que me dijo un pariente cercano del viejo Lord Shaftesbury cuando estaba este último hablando un día con el Mayor Wildman acerca de las muchas sectas religiosas en el mundo: llegaron por fin a la conclusión de que, a pesar de las infinitas divisiones causadas por el interés de los clérigos y la ignorancia del pueblo, todos los hombres sabios son de la misma religión. A esto, una mujer de la habitación, que parecía más interesada en su labor de costura que en sus palabras, preguntó con cierto interés cuál era esa religión. A lo que Lord Shaftesbury directamente replicó: "Madame, los hombres sabios nunca lo dicen». Y, verdaderamente, considerando qué peligroso es decir la verdad, es difícil conocer cuándo un hombre declara sus verdaderos sentimientos sobre las cosas. ${ }^{26}$

Esto ha llevado a algunos estudiosos a plantear que el lenguaje de Toland es irónico, que está lleno de trampas, que enmascara su pensamiento, que es solo una pose o que es una farsa. ${ }^{27}$ Uno de los que defiende con más ardor este tipo de posiciones es Champion:

Aprovechándose del creciente poder cultural de la imprenta y, particularmente, de la ambigüedad del texto para la recepción del lector, Toland se presentó constantemente como un erudito en teología. En vez de atacar las afirmaciones de la Biblia, de los Padres de la Iglesia y de la tradición eclesiástica, Toland llegó a ser un experto en estos discursos. Aprendiendo el oficio, llegó a ser capaz de dedicarse con mayor efectividad a sus ambiciones deconstructivas, burlándose de los lectores mediante una variedad de artimañas y ambigüedades [...] Su adopción del papel de una persona de sincero cristianismo o de un estudioso devoto, fue un modo simple, pero efectivo, de dar un rodeo para evitar la censura oficial, al mismo tiempo que de evitar la censura de la gente y la refutación hostil [...] Mediante una efectiva captación del lenguaje de los discursos ortodoxos (tanto en política como en teología), desarrolló un repertorio de ardides que deconstruían los tópicos comunes, exponían sus contradicciones y se apropiaban para sus propios propósitos del poder afectivo de palabras clave. ${ }^{28}$

Desde hace tiempo hay una línea de interpretación de la historia de la filosofía que nace de la sospecha de que en el lenguaje de algunos filósofos hay una profundidad de ideas que son diferentes e incluso contradictorias con respecto a lo que aparece en la superficie, tal como lo hace frecuentemente Nietzsche. Esta línea se focaliza predominantemente en filósofos modernos, como Descartes (véase la obra de Leroy Descartes, le philosophe au masque) o Spinoza, filósofo también frecuentemente considerado enmascarado, pues habría utilizado un doble lenguaje para que no se le pudiera perseguir. Teniendo en cuenta las declaraciones de Toland y Shaftesbury, que acabamos de ver, hay algunos estudiosos, como los ya citados Champion, Fouke o Daniel, que han interpretado así las obras de Toland.

Ahora bien, si se acepta que el pensamiento de determinados filósofos está enmascarado y que no dice lo que parece decir con las palabras, entonces ¿quién tiene la misteriosa clave para encontrar el verdadero pensamiento?

26 C: 94 y 95.

27 Cfr. Daniel 1991: 9; cfr. también Herrick 1997: 51; Bernan 1992: 255-272. Todos ellos citados por Brown 2012: 2-6.

28 Champion 2003: 14.
Cada intérprete podría decir lo que quisiera sobre ese pensadory obviar los textos. Pero el tratamiento del problema debe pasar en primer lugar, creemos, inevitablemente, por el acercamiento a las vicisitudes vitales del autor; en este caso concreto, a la vida y las circunstancias de Toland.

Al principio era un gran polemista que vivía de las discusiones en los coffehouses, que publicaba obras que creía le harían importante, que participaba en el programa político de los whigs y que fue enviado al extranjero en misiones políticas. Naturalmente en estas obras tenía que cuidarse de lo que decía, pero podemos pensar que gran parte de lo que decía era lo que pensaba, porque tenía el paraguas de poderosos protectores en su partido. En realidad, como intenta mostrar el mismo Champion, las ideas que promovía Toland no eran marginales en la Inglaterra de su tiempo, sino una corriente muy importante del debate político público. ${ }^{29}$ Cuando, al final de su vida, fue perdiendo el favor de los personajes que le protegían y le daban trabajo, ya no sentía esa seguridad y se fue refugiando en escritos que no estaban destinados a todos («exotéricos»), sino sólo a unos pocos («esotéricos»).

También tendríamos que tener en cuenta la legislación de su tiempo. En la Act of Tolerance de 1689 se ponía como límite aquello que pudiera incitar al desorden público. La Act for the more effectual suppressing of Blasphemy and prophaneness de 1698, en cambio, ya tenía en el foco no solo los desórdenes públicos, sino el contenido, pues tenía como objeto castigar a los que negasen la Trinidad en Dios, la verdad de la religión cristiana o la autoridad de las Escrituras. ${ }^{30}$ Así que podríamos decir que en Christianity Not Mysterious de 1696 no debía tener Toland tanto cuidado con lo que decía, mientras que no incitase a una rebelión abierta, lo que ciertamente no hacía. En cambio, sí debía tener más cuidado después de 1698 si negaba la Trinidad, que la religión cristiana era la verdadera, o que las Escrituras era un libro que tenía la autoridad divina. Por eso podríamos pensar que Christianity Not Mysterious respondía bastante exactamente a lo que pensaba Toland en ese momento. $Y$ también podríamos decir que al entrar el nuevo siglo, Toland, aunque tenía, como hemos señalado, importantes valedores ${ }^{31}$, empezó a tener más precauciones con lo que decía, como se nota en una carta del 22 de octubre de 1705 en que le decía a Shaftesbury que ya no discutía en sitios públicos ni iba a los coffeehouses. ${ }^{32}$ También deberíamos tener en cuenta que Tories y Whigs se estuvieron alternando en el poder desde 1690 hasta 1720, por lo que no hubo un gran periodo seguido de tiempo en el que Toland corriera mucho riesgo. ${ }^{33}$ Por último, además, habría que recordar que la mayoría de sus contemporáneos señalaban que era Toland poco prudente en la expresión de sus pensamientos, es decir, que hablaba abiertamente. ${ }^{34}$

29 Cfr. Ibídem: 238.

30 Cfr. Morillas 2008: cap. «La concepción de la filosofía y del filósofo en Toland».

31 Por eso Champion afirma que no deberíamos tener a Toland por una figura radical y marginal, sino por un individuo que se sentía cómodo en las esferas del poder (cfr. Champion 2003: 243).

32 Cfr. Morillas 2008: cap. "La concepción de la filosofía y del filósofo en Toland».

33 Cfr. Brown 2012: 10.

34 Véase la carta que escribe Molyneux sobre Toland a Locke del 27 de mayo de 1697, en Locke 1979: 132, citado en Toland 2005: 33 (introducción de T. Dragon). 
Pero, en segundo lugar, lo que es absolutamente fundamental es ver lo que él mismo dice sobre el asunto. Las obras principales en este sentido son las dos últimas que publicó en vida, en 1720, Clidophorus (que es parte de Tetradymus) y Pantheisticon. En ellas hace una distinción entre lo que se publica para el gran público (lo exotérico) y lo que se publica para unos pocos sabios (lo esotérico). Aunque Toland hace un primer avance de la distinción entre las doctrinas esotéricas y las exotéricas en las Cartas a Serena de 1704, será en Pantheisticon, un escrito esotérico pensado para que sólo algunos iniciados lo leyeran, donde más desarrolle esta idea y, sobre todo, en Clidophorus.

En Pantheisticon, a veces es un tanto negativo para esa filosofía exotérica, como cuando dice que «para los panteístas hay dos clases de filosofía, la externa o popular, acomodada a los prejuicios, y la interna, o pura y genuina». ${ }^{35}$ $Y$ un poco más adelante dice que "hay que hablar con el pueblo y pensar con los filósofos». Parecería así que las obras para el gran público no reflejarían su verdadero pensamiento. Pero, por otra parte, afirma la posibilidad de que haya sabios que también pertenezcan a alguna de las religiones existentes, con tal de que esta no sea cruel y tiránica, lo que significa que no habría tanta contraposición entre los pensamientos internos y la religión externa. Por otra parte, en esta obra da explícitamente cuatro consejos: 1) no chocar frontalmente con la teología tradicional (para no perjudicarse a sí mismo), pero no permanecer en silencio si se presenta la ocasión de hablar sin riesgo para su vida; 2) en cuanto a la mayoría de las palabras y dichos del Mesías, hay que aceptarlos siempre, pero sin falsas adiciones ni siniestras interpretaciones, lo que suele hacer la jerarquía religiosa; 3) en cuanto a temas de política, astronomía, mecánica o economía y ciencias semejantes, no hay que ser renuentes en hablar a los otros, sino que hay que hablar de ellos, aunque con precaución; 4) en cuanto a la naturaleza de Dios y del alma, el sabio debe pensarlos en el silencio de su corazón y no hacer partícipes de estos temas esotéricos a los malvados e ignorantes, sino sólo a los hermanos y a los sabios, y esta reserva hay que mantenerla hasta que se tenga la completa libertad de «pensar lo que se quiera y de decir lo que se piensa». ${ }^{36}$

Según esto, recordando que es una obra que sólo pensó para ser leída por pocos, controlando su edición y su difusión, y no tendría por qué engañar sobre su pensamiento, Toland no cuestiona el verdadero mensaje de Jesús (siempre que no tenga añadidos corruptores de las jerarquías eclesiásticas). Afirma, además, que se puede escribir para el gran público enfrentándose frontalmente contra la teología tradicional siempre que se presente una ocasión sin riesgo para la vida, y que en temas científicos y políticos se puede escribir para el gran público, aunque con algunas cautelas. Realmente sólo excluye de la circulación pública los temas de la naturaleza de Dios y del alma; en su caso, podríamos decir, el panteísmo que fue configurando a partir de 1700.

En Clidophorus Toland también sienta unos principios hermenéuticos para leer pensadores que escriben

\footnotetext{
35 Toland 2006: 134.

36 Ibídem: 140-141.
}

sintiéndose en peligro. Señala que, aunque es difícil saber cuándo alguien dice la verdad, mientras no haya una total libertad, sin embargo:

[...] hay una observación con la que hacer un juicio probable sobre la sinceridad de los otros cuando declaran sus opiniones. Es ésta: cuando un hombre mantiene lo que es comúnmente creído o profesa lo que es públicamente impuesto, no es siempre una regla segura que lo que él dice es lo que él piensa; pero cuando él seriamente mantiene lo contrario de lo que por ley está establecido y abiertamente se pronuncia por lo que la mayoría rechaza, entonces hay una fuerte presunción de que él pone en circulación verdaderamente su mente. $^{37}$

Por otra parte, Toland también señala que el verdadero filósofo no dice nada que sea contrario a lo que internamente piensa: «No decir con toda claridad lo que tú piensas o hacerlo mediante circunloquios y figuras es una cosa, pero es otra cosa totalmente diferente hablar positivamente contra tu propio juicio o contra la verdad mediante cualquier figura literaria». ${ }^{38}$

A veces los sabios, ajustándose a la naturaleza de las cosas y siendo consecuentes con la verdad, comunican su pensamiento, «con las puertas casi cerradas y todo tipo de otras precauciones, sólo a los amigos y conocidos que son honrados, prudentes y capaces». ${ }^{39}$ Pero con toda claridad Toland critica el que se cuenten fábulas religiosas al pueblo, incluso por su propio bien, pues «el horror de la superstición nunca produce ningún bien y sólo ha sido útil para los sacerdotes y los príncipes $»{ }^{40}$ Por ello parece Toland poner un límite al lenguaje exotérico: «nunca puede defender fábulas supersticiosas». ${ }^{41}$ Lo que vendría a significar que Toland nunca en sus escritos exotéricos incurrió en esto que critica: no defiende allí cosas que él pensase que eran supersticiones. De lo contrario, su obra no se diferenciaría de los escritos de la jerarquía religiosa que ocultaban los misterios y corrompían los textos. ${ }^{42}$

Finalmente, habría que añadir que Toland se pasó su vida criticando el manejo tramposo que las jerarquías eclesiásticas hacían de las palabras. Él lo califica de "sofistería», "artificio deshonesto» y «lenguaje indecente». Por eso, para él, «restaurar en las palabras sus significados genuinos y mantenerlos constantes es el trato más justo, el más seguro, el mejor para acabar con las discusiones y para disentir unos de otros sin faltar a la caridad ${ }^{43}$

Podríamos decir, en conclusión, que la posición de Toland es muy compleja, pero se podría resumir en los siguientes principios hermenéuticos: lo que critica de la religión de su tiempo responde a su verdadero pensamiento; lo que propone de política responde a sus auténticas intenciones; sus genuinos conceptos sobre la naturaleza de Dios y del alma, sobre todo, a partir de 1700 , deben ser buscados en sus escritos esotéricos.
37 C: 96.
$38 \mathrm{C}: 66$.
$39 \mathrm{C}: 81$.
$40 \mathrm{C}: 82$.
41 C: 87.
42 Cfr. Brown 2012: 7
43 Toland 1726c: vol. II, 128-129. 
EL PAPEL DE LA RAZÓN EN LA RELIGIÓN Y LA CRÍTICA DE TEOLOGÍA POLÍTICA CONSERVADORA

En la segunda mitad del siglo XVII mientras las guerras de religión asolaban Europa causando una gran conmoción en todos los espíritus, sobre todo en los intelectuales, al mismo tiempo se estaba produciendo un considerable avance en la ciencia y la «racionalización» del mundo. Y en este ambiente no es de extrañar que se volvieran a examinar $a b$ initio las relaciones entre razón y fe. El Tractatus Theologico-Politicus de 1670 de Spinoza supone uno de los puntos culminantes de este proceso. Otro es The Reasonableness of Christianity de 1695 de Locke, cuyo objetivo principal era «que pudieran entender las ventajas del cristianismo aquellos que dudaban y los deístas ${ }^{44}$, que pensaban que el cristianismo era superfluo y bastaba con la religión natural o racional. Para ésos, Locke quiere mostrar que el verdadero cristianismo es razonable y no tiene nada que repugne a la razón y, por tanto, a la religión natural. Además afirma que, «como la mayor parte de la gente no puede seguir las intrincadas vías de los razonamientos y además las pasiones de los hombres debilitan la luz natural de la razón para encontrar las normas éticas, es más fácil vivir una vida buena siguiendo las enseñanzas de las Escrituras». ${ }^{45}$

Parece que Locke adelantó la publicación de su obra sabiendo que Toland iba a publicar otra en la que, siguiendo su epistemología, iba a ir más allá de lo que él quería. ${ }^{46}$ Ese libro de Toland, Christianity Not Mysterious, tiene un subtítulo muy significativo: Cristianismo no misterioso o Tratado que enseña que no hay nada en el Evangelio contrario a la razón, ni por encima de ella y que ninguna doctrina cristiana puede ser llamada "misterio» con propiedad. El objetivo de la obra es, pues, demostrar que no hay nada que no sea razonable en el cristianismo y que, por tanto, todo es accesible a la razón de cualquier persona. Por ello, dirá más adelante, los cristianos, incluso los más sencillos, no necesitan expertos en misterios que les guíen. Dice que quiere «atacar al mismo tiempo el fanatismo religioso y el impío ateísmo ${ }^{47}$, pero el verdadero enemigo para él son aquellos clérigos y teólogos que añaden al cristianismo misterios y cosas difíciles de entender para proponerse a sí mismos como maestros y, así, tener poder sobre la gente. ${ }^{48}$

Cuando Toland dice que la verdadera religión debe ser razonable, no quiere decir sólo que la fe pueda ayudarse de la razón para presentarse de una manera acorde con ella o que la revelación y la razón no se contradigan. Para Toland la razón no es un mero instrumento de la revelación, sino su criterio; es la regla de la fe. Y esto es así porque "la razón es el único fundamento de toda nuestra certeza, de manera que, igual que sucede con los fenómenos de la Naturaleza, tampoco lo revelado puede estar eximido de esta regla racional». ${ }^{49} \mathrm{El}$ criterio de la fe no es una iluminación interior emocional de unos doctores que dirigen la comunidad, ni una filosofía concreta, ni la tradición de los Padres de la Iglesia, ni la jerarquía eclesiástica, pues en todos estos casos habría

\footnotetext{
44 Locke 1824a: vol. VI, 164.

45 Locke 1824b: vol. VI, 139-140.

46 Cfr. Dragon 2009: 31 y 37.

47 CNM: VII.

48 Cfr. Toland 2005: 9 («Avant-Propos» de T. Dragon).

49 CNM: 5 y 6.
}

siempre un grupo de privilegiados que le diría al pueblo cómo tiene que vivir su vida. La relevación no es el motivo ni el fundamento o el criterio de la fe, sino solo un medio de información. No debemos confundir el medio por el que llegamos a conocer algo con los fundamentos que tenemos para creerlo. Si alguien informa de algo, el receptor no lo cree por la autoridad de la palabra del informante, sino por la evidencia de las ideas mismas que le dice. Las creencias se producen, no por la pura autoridad del que habla, sino por la clara concepción que el oyente forma de lo que se dice: ese es el fundamento de la creencia. ${ }^{50}$ Si una doctrina es contraria a la razón, entonces no significa nada, no tenemos ningún tipo de idea de ella. Es como no decir nada, es algo sin sentido. ${ }^{51} Y$ "si no se puede entender lo que cree, no puede haber asentimiento y fe sincera». ${ }^{52}$ Tener confianza en algo sin entenderlo, sin ver que es algo racional, no es fe o persuasión, sino «precipitada presunción y un obstinado prejuicio más propio de entusiastas o impostores que de seres enseñados por Dios» ${ }^{53}$; «es una credulidad reprobable y una posición temeraria que se funda generalmente en la disposición intencionada a ser un ignorante y se mantiene por las perspectivas de obtener ganancias». ${ }^{54}$ Puede haber muchas personas que digan que Dios les ha revelado algo; la única manera que tenemos de discriminar la verdadera revelación de Dios de los engaños e imposturas de los hombres es analizar los contenidos de lo que se trasmite y ver si son contenidos racionales en los que está presente la sabiduría de Dios: «la sana razón y la divina sabiduría, que se manifiesta en los contenidos, son el único criterio para distinguir la verdadera revelación divina de los engaños y tradiciones humanas». ${ }^{55}$

Pero esto no significa que la razón esté por encima de la revelación, como no lo está la gramática griega por encima del Nuevo Testamento: «nos servimos de la gramática para entender el lenguaje del Nuevo Testamento y de la razón para comprender su sentido». ${ }^{56}$ Toland no propone, como otros lo habían hecho ${ }^{57}$, que la revelación se acomodase a la razón y que la filosofía fuera el intérprete de las Escrituras. No se necesita la mediación de sistemas filosóficos ni de una clase privilegiada, los filósofos, para comprender las Escrituras. Toland no quiere reducir la enseñanza de las Escrituras a la razón deísta filosófica. ${ }^{58} \mathrm{Ni}$ comparte ninguna suerte de averroísmo que indicase que el verdadero conocimiento está en la razón y que la fe es sólo para la gente sencilla. $Y$ esto es así porque su concepto de razón no es racionalista, sino pragmático, empirista y cercano a las ciencias naturales. Toland transporta al estudio de las Escrituras los métodos epistemológicos de las ciencias de la naturaleza. ${ }^{59}$ Para él la comprensión racional de algo consiste sólo en «conocer sus propiedades sensibles, sus

\footnotetext{
50 Cfr. CNM: 38 y 39.

Cfr. CNM: 29.

52 CNM: 36.

53 CNM: 127.

54 CNM: 37.

55 CNM: 41 y 42.

56 CNM: 140.

57 Véase la obra de Louis Meyer Philosophie Sacrae Stripturae interpres exercitatio de 1666.

58 Cfr. Toland 2005: 85.

59 Cfr. Ibídem: 102.
} 
usos prácticos y lo que se puede deducir de esto $»^{60}$, pues «la razón no implica el conocimiento completo de las cosas». ${ }^{61}$ «Nos basta con saber las propiedades que el agua tiene para nuestra vida; para beberla no necesitamos conocer las más pequeñas partículas que la componen $"{ }^{62} Y$ esta concepción de razón se aplica también a los asuntos religiosos ${ }^{63}$ : "la revelación no nos quiere hablar de la esencia de Dios, ni de aspectos divinos que no afectan a nuestra vida, sino de aquello de Dios que es útil para nuestra existencia». ${ }^{64}$ Por eso, «el ser divino no es más misterioso que la más pequeña de sus criaturas ${ }^{65}$, pues con el único método de conocer que tenemos debemos buscar siempre lo que es útil para nuestra vida, las propiedades de las cosas que tienen relación con nuestro vivir, no lo que los seres son en sí mismos, sus esencias (algo en lo que Dios sí excedería infinitamente a cualquiera de sus criaturas, que nos sería inútil). ${ }^{66}$ Lo que se refiere a nuestra vida es lo moral, por lo que Toland tiene una visión moral de la religión cristiana: «la esencia misma del cristianismo consiste en la más perfecta moral». ${ }^{67}$ Las dimensiones cultual y dogmática de la religión parecen que no son algo importante para él. $Y$ es una moral esencialmente social, que consiste en amor mutuo, tolerancia y paz social ${ }^{68}$, pues, aunque en sí mismo no hay nada absolutamente bueno o malo, nos dice, "las acciones son buenas o malas si benefician o perjudican a los seres humanos». ${ }^{69}$

En su relación con la naturaleza, a partir de sus experiencias, el hombre va formando ideas y nociones comunes, que son válidas para todos los hombres. ${ }^{70} \mathrm{La}$ razón es «el buen uso de esas facultades de formar ideas y de compararlas entre sí y de amar lo bueno y evitar lo malo». ${ }^{71} \mathrm{Y}$ a partir de esas nociones comunes el hombre va juzgando lo que se le presenta para ver si es racionalmente aceptable o no. Así también la razón evalúa si lo que se nos revela en la religión es consistente con las nociones comunes que tenemos del resto de las cosas naturales. ${ }^{72}$ Toland piensa que "la religión cristiana es tan conforme con nuestras nociones comunes como lo es el conocimiento de la piedra, el aire o el agua». ${ }^{73}$

Ahora bien, cuando Toland dice que el Evangelio es inteligible no quiere decir que eso se consiga sin esfuerzo y sin trabajo, sino que, como con cualquier otro libro, debemos esforzarnos para llegar a entenderlo. ${ }^{74}$ Pero afirmar que la razón necesita constancia y esfuerzo no supone aceptar que nuestro entendimiento está en su naturaleza corrompido,

\footnotetext{
${ }^{60}$ CNM: VII.

${ }^{61}$ CNM: 74 y 79.

62 CNM: 77

${ }^{63}$ Cfr. CNM: 86.

${ }^{64}$ CNM: 79. Cfr. Toland 2005: 71.

65 CNM: 87

66 Cfr. CNM: 75 y 76.
}

67 Toland 2004b: 241-242. Parallèle es un texto que tenía Leibniz y que parece ser una traducción suya de un texto de Toland que se ha perdido.

${ }^{68}$ Cfr. Jaffro 2012: 82 y ss.

69 Toland 1709: 72

70 Cfr. Toland 2004c: 65-66. Nazarenus. A partir de ahora utilizaremos esta edición con la sigla «N».

71 CNM: 9.

72 Cfr. CNM: 79

73 CNM: 25; cfr. CNM: 46 y 79.

74 Cfr. CNM: 138. como señalaban las doctrinas del pecado original. El problema, para Toland, es que algunos, «no queriendo reconocer su ignorancia y sus fallos (que proceden de sus pasiones, su pereza o su insensatez), se quieren descargar de toda responsabilidad y echan la culpa a una impotencia natural, cuya curación estaría por encima de sus fuerzas». ${ }^{75}$ Pero si suponemos una impotencia natural de la razón, porque está corrompida, entonces admitiremos que hay cosas que tenemos que creer, aunque no las entendamos y nos parezcan irracionales, por lo que ya no habrá nada irracional a lo que nos podamos oponer, pues nos dirán que proviene de Dios, y los clérigos se propondrán a sí mismos como representantes de Dios con poder para explicárnoslas y decirnos lo que tenemos que creer. $^{76}$

Una vez que hemos visto la relación entre razón y revelación en Toland, podemos pasar a un importante corolario de esta concepción. Si la razón es el criterio y la regla de la fe, siendo así que la razón es algo natural de todos los hombres, entonces tendremos que pensar que el contenido de la revelación es accesible a todos los hombres. ${ }^{77}$ Parece, señala Toland, que "Cristo tenía una especial predilección por la gente sencilla; predicó para ella y, sin ninguna duda, la gente sencilla entendió sus instrucciones mejor que las misteriosas charlas de los sacerdotes $" .^{78}$ Incluso podríamos decir que Cristo operó como una especie de traductor para que toda la revelación fuera accesible a la razón incluso de las gentes más sencillas. Por eso dice Toland que Jesucristo desnudó la verdad de todas aquellas cosas que la hacían difícil (complejidades dogmáticas y culturales) y «la convirtió en algo sencillo para las pequeñas capacidades». ${ }^{79}$ Esta idea de que todos, hasta los más sencillos, pueden ser jueces del verdadero sentido de la religión rompe con la idea de autoridad tradicional y tiene un componente revolucionario para aquella época: lo importante es que cada uno se haga director de su propia vida. Y esta atención a la gente sencilla es tan importante que Toland mismo dice que él «ha escrito esta obra no sólo para los filósofos, sino también para el vulgo, al que de ninguna manera olvida». ${ }^{80}$

Podríamos decir que este análisis de las relaciones entre fe y razón y la afirmación de una religión para todos tiene un objetivo claramente político en contra de las jerarquías religiosas y el poder político legitimado en la religión tradicional. Toland hace una genealogía histórica del poder sacerdotal y en cierta media anticipa la incipiente sociología del conocimiento del siglo XIX. ${ }^{81}$ El momento capital fue, indica, cuando el cristianismo se convirtió en la religión oficial y mucha gente entró en él por la voluntad del emperador y no por la propia conciencia e introdujo en el cristianismo todo tipo de cosas paganas. Así se creó una clase sacerdotal con donaciones, riquezas y dignidades, como en el paganismo. De esa manera el cristianismo se llenó de misterios, que los laicos no podían comprender y que requerían, para su

75 CNM: 61.

76 Cfr. CNM: 26-28.

77 Cfr. Espinosa 2015: 121-155.

78 CNM: 141 y XIX. Esta idea aparecerá en diversas obras posteriores como en Nazarenus (cfr. Toland 2004c: 33).

79 CNM: 151.

80 CNM: XVII. También habría que recordar aquí su proyecto de crear un periódico semanal para todos, especialmente para las mujeres (Toland 1726b: 201-215; cfr. Champion 2003: 245).

81 Cfr. Clarke 1997: 298. 
explicación, de los sacerdotes, supuestos mediadores entre Dios y los hombres, que así adquirieron un poder inmenso, al exigir el monopolio de la interpretación de la revelación. Al final los clérigos se atribuyeron a sí mismos «el derecho de ser los únicos en interpretar las Escrituras y reclamaron la infalibilidad para sí mismos».82 $\mathrm{Y}$ así hemos llegado a la situación actual, en la que los clérigos dicen que hay en la Biblia misterios y que nosotros, los laicos, señala Toland, no podemos interpretar correctamente la Biblia por nuestro corrupto y limitado entendimiento. Una vez que admitamos ese principio, tendremos que aceptar que incluso lo más claro y sencillo está lleno de misterios, «de manera que dependeremos constantemente de ellos para que nos lo expliquen $»{ }^{83}$ Pero esos manejos son totalmente contrarios a la religión cristiana: «contra el poder sacerdotal no hay nada más satírico que el evangelio de Cristo». ${ }^{84}$

Esta crítica a las jerarquías religiosas se intensifica en sus obras posteriores..$^{85}$ No se trata de una crítica de las equivocaciones de los sacerdotes en cuanto a sus concepciones religiosas, sino, sobre todo, de su poder. El anticlericalismo de Toland, aunque articulado frecuentemente en un lenguaje teológico, es algo político, pues su foco estaba más en la política nacional que en tener una vaga influencia cultural y religiosa en la opinión pública. ${ }^{86}$ Por eso, el blanco de sus ataques es, sobre todo, la jerarquía de la confesión anglicana. Él mismo explicita la relación entre razonabilidad del cristianismo y política cuando dice en su Apología, que escribió para defenderse de los ataques que estaba recibiendo su obra, que «lo que no está fundado en la razón es irracional y por tanto tiránico». ${ }^{87} Y$ es que para Toland el primer apoyo de la tiranía estaba en la jerarquía religiosa ${ }^{88}$ que socavaba el poder de la razón. Podríamos decir con Champion que, para él, «el fundamento de la tiranía tenía apoyos teológicos más que civiles o jurídicos». ${ }^{89}$

Y en esta batalla teológico-política Toland quiere proponer una nueva concepción de la relación entre el individuo y el grupo, una nueva concepción de la identidad colectiva. En su obra Nazarenus señala que los primitivos cristianos, siguiendo el ejemplo de Jesucristo, permitieron que los judíos siguieran observando la Ley al mismo tiempo que siendo cristianos, y critica que eso mismo ya no se permitiera posteriormente. $\mathrm{Y}$ dice: «Aquí puedes ver la

82 CNM: 167. Toland narra toda esa historia en CNM: 155-167.

83 CNM: 26-28.

84 Toland 1726c: vol. II, 138.

85 Veamos algunos ejemplos: «Ellos [los clérigos] hacen discursos contra la razón humana, no, como hipócritamente pretenden, para hacer que los hombres se sometan a la palabra de Dios, algo que la razón siempre nos aconseja, sino para sujetar a los hombres a su propia autoridad y para disponer arbitrariamente de sus creencias" (Hodegus, que es parte de Tetradymus, en Toland 2004a: pref., XIX); "Cada día se producen nuevos ejemplos de los planes ambiciosos y traidores de clérigos degenerados cuyas vidas hacen ateos y cuyas doctrinas, esclavos. El propósito último de tales hombres es procurarse a sí mismos riquezas y consiguientemente poder y autoridad; y en orden a asegurarse eso, educan a sus oyentes en la ignorancia, $y$, por ello, en la superstición y en el fanatismo» (N: pref., XV); «la ignorancia de los laicos son los ingresos de los clérigos» (C: 89). Podríamos decir que es casi imposible encontrar una obra de Toland en donde no aparezcan este tipo de críticas.

86 Cfr. Champion 2003: 13 y 243. Cfr. Dragon 2009: 10.

87 Toland 1997a: 116

88 Cfr. Toland 1698: pref. 2-3.

89 Champion 2003: 248. antigüedad de la presión de la uniformidad y sus efectos»..$^{90}$ En el mismo sentido en el prefacio propone la fórmula de "unión sin uniformidad» ${ }^{91}$ para referirse a que pueden convivir diferentes maneras de ser cristiano sin perderse la unidad entre ellas. Por eso también critica el que alguien sea rechazado del grupo sólo porque no concuerda en una idea con los que tienen el poder y se creen en la posesión de la ortodoxia: cuando alguien se enfrenta con ellos en una pequeña parte, afirma, «ellos se sienten obligados a tratarlos como opuestos en todo ${ }^{92}$, lo que denota que lo importante es la homogeneidad de la identidad colectiva:

Si, por ejemplo, eres luterano, aunque concuerdes con los de tu confesión en los artículos principales, tus enemigos, cuando se presente la ocasión, no dejarán de acusarte por lo que disientes de ellos [...] No sólo se sentirán ofendidos, sino que podrán incluso dudar de tu sinceridad sobre todos los artículos, lo cual es el carácter normal de la mayoría de las confesiones [...] Hay gente que, olvidando que están despreciando a la verdadera religión, tratan como perniciosos heréticos o insufribles ateos a los que muestran la más mínima falta de aceptación de las cosas que ellos han añadido al cristianismo. ${ }^{93}$

Toland está suponiendo que las comunidades no deberían tener una homogeneidad que aprisiona a los diferentes y da poder a los guardianes de esa homogeneidad. La acusación de ateísmo que lanzan los detentadores de la ortodoxia lo que significa es que a aquellos que difieren en algo se les acusa de rechazar toda la religión y al mismo Dios, incluso aunque sean buenas personas; mientras que si alguien, aunque sea mala persona y un total ignorante de la religión, es devoto de los intereses de esos detentadores de la ortodoxia, entonces es calificado de «buen hombre de Iglesia». ${ }^{94}$ Realmente para Toland "ateo» no se le ha achacado a él, y a otros como él, por su significado semántico, sino por la carga de agresividad que conlleva, pues llamar a alguien «ateo» era igual que llamarle «hijo de puta», ya que el adjetivo "ateo» sólo significa que «alguien se está sintiendo muy contrariado con otros que disienten de él y son diferentes». ${ }^{95}$

Probablemente muchos actores de este momento histórico, tanto supuestos ortodoxos como heterodoxos, tienen claro que son incapaces de definir con total nitidez los límites de la fe y la herejía ${ }^{96}$, pues era una cuestión que requería unos conocimientos realmente extraordinarios. Así que, en realidad, el problema no eran las meras ideas, sino las ideas en cuanto símbolos de que se quiere ser miembro de esa identidad colectiva y se es capaz de someter el propio pensamiento y la propia palabra para ello. El credo, resumen de los dogmas cristianos, era llamado

$90 \mathrm{~N}: 56$.

91 Ibídem: pref., V.

92 Toland 2004a: 13, 56 y 70.

93 CNM: XXVII-XXVIII. Véase también Toland 2004a: 67. Clidophorus.

$94 \mathrm{~N}$ : pref., $\mathrm{XXI}$.

95 Toland 1997b: 164.

96 Cfr. Mckenna 2002: 149. Véase por ejemplo también la frase de Toland: «Difamación, exilio, prisión y muerte a veces no fueron considerados castigos suficiente [] por no creer en doctrinas que nadie entendía o, si eran entendidas, se trataba de doctrinas que no contribuían ni un ápice a hacer a los hombres más sabios o mejores personas» (Toland 1724: 113). 
antiguamente "símbolo», en el sentido de que era una especie de "contraseña» que ayudaba a identificar si una persona pertenecía a la comunidad religiosa. Si el criterio de definición de lo que es la verdadera religión y la identidad colectiva está en los que tienen autoridad para interpretar infaliblemente las Escrituras, entonces el poder está en ellos, y también el control de la identidad colectiva. Poner, en cambio, en la razón el criterio de verdad significa darle el poder al individuo que piensa, potencialmente a todos los individuos, y aceptar que la identidad colectiva se construye desde la libertad de los individuos. Y este fue el principal objetivo de Toland: depurar al cristianismo de las injerencias del poder teológico-político y posibilitar una comunidad política libre. ${ }^{97}$

\section{FUENTES}

Obras de Toland ${ }^{98}$

Toland, J. 1696. Christianity not Mysterious. London: Buckley. Disponible en: https://books.google.es/books?id=fHhOAAAAcAAJ \&printsec=frontcover\&hl=es\&source=gbs_ge_summary_r\&cad $=0$ $\# v=$ onepage\&q\&f=false [consultado el 20/05/2017].

Toland, J. 1698. A defence of the Parliament of 1640. Disponible en: http://tei.it.ox.ac.uk/tcp/Texts-HTML/free/A62/A62847.html [consultado el 20/05/2017].

Toland, J. 1701. Anglia libera. London: Lintott.

Toland, J. 1709. Adeisidaemon. Den Haag: Johnson.

Toland, J. 1724. Reason for Naturalizing the Jews in Great Britain and Ireland. London: Roberts. Disponible en: https://ia800201. us.archive.org/26/items/reasonsfornatur00tolagoog/reasonsfornatur00tolagoog.pdf [consultado el 20/05/2017].

Toland, J. 1726a. «Another Memorial for the Most Honourable The Earl of ***», en P. Des Maizeaux (ed.), A Collection of Several Pieces of Mr. John Toland: vol II, 220-238.

Toland, J. 1726b. "A project of a journal», en P. Des Maizeaux (ed.), A Collection of Several Pieces of Mr. John Toland: vol II, 201-214. London: Peele.

Toland, J. 1726c. "The Primitive Constitution of the Christian Church», en P. Des Maizeaux (ed.), A Collection of Several Pieces of Mr. John Toland: vol II, 120-200. London: Peele.

Toland, J. 1997a [1697]. «Apology», en Ph. Mcguinness, A. Harrison y R. Kearney (eds.), John Toland's Christianity not Mysterious. Text, associated works and critical essays: 109-135. Dublin: The Lilliput Press.

Toland, J. 1997b [1702]. «Vindicius Liberius, or Mr. Toland's Defence of Hinself», en Ph. Mcguinness, A. Harrison y R. Kearney (eds.), John Toland's Christianity not Mysterious. Text, associated works and critical essays: 153-197. The Lilliput Press.

Toland, J. 2004a [1720]. "Tetradymus» [Compuesto de Hodegus, Clidophorus, Hypatia y Mangoneutes], en Anónimo (ed.), The Theological and Philological Works of the Late Mr. John Toland: Being a System of Jewish, Gentile and Mahometan Christianity: I-XXII y 1-226. Whitefish: Kessinger Publishing's Rare Reprints.

Toland, J. 2004b [1701]. «Parallèle entre la raison originale ou la loi de la nature, le paganisme ou la corruption de la loi de la nature, la loi de Moïse ou le paganisme reformé, et le christianisme ou la loi de la nature rétablie», en J. Toland, Lettres à Serena et autres textes: 237-278. Paris: Champion. [Ed. de T. Dragon].

Toland, J. 2004c [1718]. "Nazarenus», en Anónimo (ed.), The Theological and Philological Works of the Late Mr. John Toland: Being a System of Jewish, Gentile and Mahometan Christianity: I-XXV y 1-8, 1-57, 1-16.

97 Cfr. Espinosa 2008: 1-41.

98 Cuando no coincide con la edición utilizada, pongo en corchetes la primera edición o la fecha de composición
Toland, J. 2005 [1696]. Le Christianisme sans mystères. Paris: Champión. [Ed. introducción y notas de T. Dragon].

Toland, J. 2006 [1720]. Pantheisticon. Paris: La Luminade y Le Bord de I'Eau. [Trad. al francés, rev. y present. de A. Peillon].

Compilaciones de obras de Toland

Anónimo (ed.). 2004. The Theological and Philological Works of the Late Mr. John Toland: Being a System of Jewish, Gentile and Mahometan Christianity. Whitefish: Kessinger Publishing's Rare Reprints [ed. facsim. de la edición de Mears de 1732].

Des Maizeaux, P. (ed.). 1726a. A Collection of Several Pieces of Mr. John Toland. London: Peele.

Mcguinness, Ph., Harrison, A. y Kearney, R. (eds.). 1997. John Toland's Christianity not Mysterious. Text, associated works and critical essays. Dublin: The Lilliput Press.

\section{Otras Fuentes}

Des Maizeaux, P. 1726b. "The life of M. Toland», en P. Des Maizeaux (ed.), A Collection of Several Pieces of Mr. John Toland: vol. I, IIIXCII. London: Peele.

Locke, J. 1824a. «A Vindication of The Reasonableness of Christianity from Mr. Edwards's Reflections», en J. Locke, Works: vol. VI, 159190. London: Rivington [1 1 ed. 1695].

Locke, J. 1824b. "The Reasonableness of Christianity as delivered in Scriptures», en J. Locke, Works: vol. VI, 1-158. London: Rivington [1a ed. 1695].

Locke, J. 1979. The correspondence of John Locke. Oxford: Clarendon.

Shaftesbury, Anthony Ashley Cooper, Conde de. 2001. "Sensus communis: an Essay on Freedom of Wit and Humour», en Shaftesbury, Anthony Ashley Cooper, Conde de., Characteristics of Men, Manners, Opinions and Times: 46. Indianapolis: Liberty Fund. [1a ed. 1709] [ed. Douglas den Uyl a partir de la edición de 1737].

\section{BIBLIOGRAFÍA CITADA}

Bernan, D. 1992. "Disclaimers and Offence Mechanisms in Charles Blount and John Toland», en M. Hunter y D. Wooton (eds.), Atheism from the Reformation to the Enlightenment: 255-272. Oxford: Oxford Univ. Press.

Brown, M. 2012. A Political Biography of John Toland. London: Pickering \& Chatto.

Brykman, G. (ed.). 1995. "Pour en savoir plus, cherchez dans mes écrits». Revue de synthèse 2-3: 221-229.

Champion, J. 2003. Republican Learning: John Toland and the Crisis of Christian Culture 1696-1722. Manchester y New York: Manchester University Press.

Clarke, D. M. 1997. "Toland: on faith and reason», en Ph. Mcguinness, A. Harrison y R. Kearney (eds.), John Toland's Christianity not Mysterious. Text, associated works and critical essays: 293-302. Dublin: The Lilliput Press.

Daniel, S. H. 1991. "The Subversive Philosophy of John Toland», en P. Hyland y N. Sammells (eds.), Irish Writing: Exile and Subversion: 9. Houndsmills: Macmillan.

Dragon, T. 2009. Toland et Leibniz: l'invention du néo-spinozisme. Paris: Vrin.

Espinosa, J. 2008. «La religión en la esfera pública. Habermas, Toland y Spinoza». Cuadernos del Seminario Spinoza 22: 1-41.

Espinosa, J. 2015. "La secularización de lo teológico-político en Spinoza», en S. Schmidt y M. González (eds.), Religión y política en el siglo XXI: 121-155. Chihuahua: Instituto Chihuahuense de la Cultura.

Fouke, D. C. 2007. Philosophy and Theology in a Burlesque Mode. John Toland and "The Way of Paradox». New York: Humanity Books.

Herrick, J. A. 1997. The Radical Rhetoric of the English Deists: The discourse of Scepticism 1680-1750. Columbia: Univ. South Carolina.

Iofrida, M. 1983. La filosofía di J. Toland. Spinozismo, scienza e religione nella cultura europea fra '600 e '700. Milano: Franco Angeli. 
Jacob, M. 1969. «John Toland and the Newtonian Ideology». Journal of the Warburg and Courtauld Institutes 32: 307-331.

Jaffro, L. 2012. "Toland and the moral teaching of the gospel», en R. Savage (ed.), Philosophy and Religion in Enlightenment Britain: 77-89. Oxford: University Press.
Mckenna, A. 2002. «Histories of Heresy in the Clandestine Philosophical Manuscripts», en J. C. Laursen, Histories of Heresy in Early Modern Europe: 145-160. New York: Palgrave.

Morillas, J. 2008. Religión, ciencia y política en la filosofía de John Toland. Tesis doctoral. Universitat de Barcelona. En: http://diposit. ub.edu/dspace/handle/2445/35641 [consultado el 20/05/2017]. 